\section{Advertisers in this issue:}

\begin{tabular}{lr}
\hline Brimrose & back cover \\
\hline \multicolumn{3}{l}{ FEI Company } & 3 \\
\hline $\begin{array}{l}\text { High Voltage Engineering } \\
\text { Europa }\end{array}$ & inside front cover \\
\hline $\begin{array}{l}\text { International Scientific } \\
\text { Instruments }\end{array}$ & 5 \\
\hline Lake Shore Cryotronics & 14 \\
\hline National Electrostatics & 13 \\
\hline Society of Vacuum Coaters & 51 \\
\hline SSC Inc. & 11 \\
\hline UHV Instruments inside back cover \\
\hline Vacuum Barrier Corporation & 12 \\
\hline Virginia Semiconductor & 9 \\
\hline Voltaix & 8 \\
\hline
\end{tabular}

\section{In the February issue...}

\section{Guest Editor Troy W. Barbee} Jr., Chemistry and Materials Sciences Department, Lawrence Livermore National Laboratory, focuses on multilayer materials:

\section{"Multilayer Optics for the} Soft X-Ray and Extreme Ultraviolet," by Troy W. Barbee Jr.

\section{"Metastable Phase Formation in Thin Films and Multilayers," by Bruce M. Clemens and Robert Sinclair, Stanford University.}
"Artificially Layered Super- conductors," by Ivan K. Schul- ler and Julio Guimpel, Physics Department, University of California, San Diego; and Yvan Bruynseraede, Katho- lieke Universiteit-Leuven, Belgium.

\title{
The Omni-Competence Trap
}

"Oh, You're a scientist! You must be very smart! Will you explain to my kids why the sky is blue. You know, they're always asking these questions that I can't really answer. I guess they think parents know everything. Isn't that cute!"

"Kids, the sky is blue because when the light from the sun (which has all the colors mixed up in it) hits the air around the earth, some colors...the bluer colors...get scattered....uh,'I mean get bumped...out of the direction they were going and wind up down here where we see them."

"But why does blue get bumped?"

"That's a very good question. Why don't you ask one of your parents."

They say a little knowledge is a dangerous thing. They should also have said that a lot of narrow knowledge gives a misleading impression. It is the illusion of global competence. Scientists and engineers give the impression of being very knowledgeable. If they have earned advanced degrees, had postdoctoral training, and taken sabbaticals, they appear to have spent all their time in school. Therefore, they must be absolutely brilliant about everything.

Of course, this sounds silly to those of us who are the scientists and engineers. We are constantly encountering our own limits as we try to do something new, or even remember something old. But the lay public, believe it or not, are often unreasonably impressed by us. We may not be asked for a legal or medical opinion-those distinctions of field are clear, probably because people use the services of lawyers and doctors directly. But the rest of us are lumped together into a perceptual technical melting pot.

Aside from the occasional embarrassment when you can't explain plate tectonics, the precession of the perihelion of Mercury, or the difference between PCBs and PVC to your next door neighbor, what harm is there in being perceived as omni-competent?

Well, the image of science gets a little tarnished when so-called experts disagree in public. We try to explain that it is in the nature of science to challenge assumptions and debate alternatives until the cows come home. True enough! However when the boundary gets fuzzy between debate over technical questions with no solid theoretical answers and subjective differences of opinion on issues with political content, a line has been crossed. The respect-the awe-which the technical expert commands adds credence, deservedly or not, to every utterance.
When the same physicist who tells me that the Strategic Defense Initiative involves the use of devices that can't work also tells me that the strategy is misguided, is this physics or policy expertise? When the same materials scientist who tells me that we can just about make good high temperature superconducting SQUIDs also tells me that they will be the first successful HTS product, is this materials or marketing expertise? There does need to be some good means for technical experts to contribute what they know to the education of the public and the policymakers-a means that doesn't require one individual to be expert in his or her technical nonspecialities, nor that gives undue weight to nontechnical biases.

This may be a problem with no solution in the science and technology policy arena. Most often the imagined solution is to use committees of established experts. A committee must comprise a manageable number of members to be effective in a finite time. With the very large number of relatively narrow subspecialities in science and technology, how many experts would be needed to cover the gamut without serious gaps? The problem may be amenable to percolation theory. Form a composite by plopping down numbers of experts at random, with defined profiles of knowledge versus distance from speciality, into a matrix of ignorance and look for the threshold for connectivity. We will find that the required number is large.*

And so now we see how a normal committee is made. A human's capacity is finite and roughly conserved in terms of depth and breadth of knowledge. To make our number smaller, we do a volume preserving transformation by making our committee members shallow but much broader and more likely to overlap their transformed cohorts. A most practical solution and a vivid reminder that a little knowledge is a dangerous thing.

\section{E.N. KAUFMANN}

\footnotetext{
*For example, a study of scope narrowed to just the MS\&E field, lasting two years longer than initially projected and using over 100 official and many more unofficial members, produced an arguably thorough and accurate picture in a 279page report. The MS\&E Study of the National Research Council [see the October 1989 MRS Bulletin, p.27-32] paid the price of size and time to do a credible job.
} 